\title{
The Future Is Now: Incorporating Telemedicine into Glaucoma Care
}

\author{
Monica K. Ertel $^{1} \cdot$ Malik Y. Kahook $^{1}$ - Cara E. Capitena Young ${ }^{1}$
}

Accepted: 13 May 2021 / Published online: 7 July 2021

(C) The Author(s), under exclusive licence to Springer Science+Business Media, LLC, part of Springer Nature 2021

\begin{abstract}
Purpose of Review The field of teleglaucoma has expanded rapidly in recent years with several large-scale teleglaucoma screening programs in existence throughout the world. Additionally, teleglaucoma programs for use in disease management are under study. The limited access to care that resulted from the COVID-19 pandemic highlighted the need for expansion of such programs. This article reviews the literature on teleglaucoma for screening and management of glaucoma, discussing considerations for incorporating teleglaucoma into clinical practice.

Recent Findings Teleglaucoma screening reduces the rate of false-positive referrals and can accurately screen at-risk populations with accuracy similar to in-person screening. The use of teleglaucoma for the management of glaucoma shows promise for lowrisk patients with early disease. Furthermore, teleglaucoma is cost-effective and reduces travel burden for patients resulting in high patient satisfaction.

Summary Teleglaucoma offers potential for improving access to glaucoma care, reducing the burden on patients and health care systems.
\end{abstract}

Keywords Telemedicine $\cdot$ Teleglaucoma $\cdot$ Glaucoma screening

\section{Introduction}

Glaucoma is the second leading causes of worldwide blindness affecting an estimated 76 million adults in the year 2020 [1]. Since it is a disease that increases in incidence with age, the prevalence of glaucoma will only continue to grow with an aging population. In the USA alone, it is estimated that over 7 million people will carry a diagnosis of primary open angle glaucoma by the year 2050 [2]. Several major clinical trials have demonstrated that with intraocular pressure (IOP) lowering, progression of glaucoma can be slowed [3-5]. However, this requires early detection as well as frequent clinical followups for IOP monitoring, optic nerve imaging, functional visual

This article is part of the Topical Collection on Diagnosis and Monitoring of Glaucoma

Monica K. Ertel

monica.ertel@cuanschutz.edu

Malik Y. Kahook

malik.kahook@cuanschutz.edu

Cara E. Capitena Young

cara.capitenayoung@cuanschutz.edu

1 Sue Anschutz-Rodgers Eye Center, UC Health, University of Colorado, Aurora, CO, USA field testing, and adjustment of medications. One of the most cited barriers to care by populations at risk for glaucoma is transportation to these clinic appointments [6]. Telemedicine allows physicians to provide care to patients remotely and offers a potential solution to this barrier to care.

The field of telemedicine was first introduced in the USA as early as the 1960s with the development of technology that allowed for two-way communication between patient and physician [7]. Since that time, significant technological advances have allowed the field of telehealth to grow exponentially. While the exciting potential of telehealth to expand health care access to an underserved population has always been apparent, the potential importance of telehealth for routine care became clear over the last year. The COVID-19 pandemic limited access to routine health care services for a significant proportion of the population across the world, uncovering the need for telehealth expansion and incorporation into clinical practices [8]. The medical community quickly recognized this need; a recent PubMed literature search reveals a doubling of publications on the topic of telemedicine in the year 2020. In the last year, many ophthalmologists have incorporated telemedicine into their clinical practice with a recent survey demonstrated that $77.4 \%$ of responding eye care providers provided telehealth services during the pandemic, despite most not doing so prior to the COVID-19 outbreak [9]. 
Teleglaucoma is defined as the use of telemedicine to provide glaucoma care to patients. The field of teleglaucoma has gained momentum in recent years with wide scale teleglaucoma programs now established in several countries. This article will review the literature on teleglaucoma, discussing its potential applications to augment the diagnosis and management of glaucoma. We will also discuss considerations for incorporation of teleglaucoma into clinical practice.

\section{Types of Telemedicine}

There are three primary modalities of delivering telemedicine services: synchronous, asynchronous, and a combination of the two. Synchronous telehealth services involve real-time video conferencing between the provider and the patient $[10$, 11•]. While this allows direct communication, the use of video conferencing to perform a physical examination has limitations. This is especially true in ophthalmology where the majority of the clinical examination is performed under the magnification of a slit lamp.

Asynchronous telehealth services employ a store and forward approach in which data acquisition is performed and then forwarded to the provider for remote assessment [10, 11•]. This approach utilizes digital images with potentially improved resolution compared to video conferencing. Furthermore, this method of telehealth allows for the acquisition of diagnostic tests such as slit lamp photos, optical coherence tomography (OCT), and visual field testing. However, there is an intrinsic risk of poor quality, uninterpretable images that limit the ability to accurately assess patients [12].

A third type of telehealth service utilizes a combination of both asynchronous data acquisition and real-time consultation. One can imagine such a clinical scenario: a patient comes in for IOP measurement, OCT, visual field testing, and optic nerve photography $[10,11 \bullet]$. This information is then transmitted to a glaucoma specialist who, after reviewing the data, calls the patient to elicit any further medical history and discuss results in a synchronous format. This most closely mimics the current face to face clinical interactions with which we are most familiar.

\section{Applications for Use}

While teleglaucoma has many potential applications, two of the most commonly utilized are triage/screening and disease monitoring $[11 \bullet, 13,14]$. When used for screening, teleglaucoma offers the potential to provide access for patients in remote locations and has the potential to identify at-risk patients in the population who can then be examined by a glaucoma specialist [13]. The efficacy and cost-effectiveness of tele-ophthalmology screening for diabetic retinopathy as a model of this application has been well-established [15-17, 18•]. The use of teleophthalmology for disease management, on the other hand, is less well-established but studies offer promising results $[19 \bullet \cdot]$. Here we will review the recent literature on these applications.

\section{Teleglaucoma for Screening}

Utilizing telemedicine for glaucoma screening has many potential benefits. In developed countries with large numbers of patients and far fewer glaucoma specialists, it can reduce unnecessary subspecialty appointments. Studies investigating the agreement between community-based optometrists and ophthalmologists based on virtual optic nerve head imaging and visual field images support that idea that communitybased screening of at-risk glaucoma patients can reduce the false-positive rate of referral to glaucoma specialists [20,21]. An alternative application of teleglaucoma is large population screening to identify at-risk patients who can then be directed to subspeciality service $[22 \cdot \bullet, 23,24]$. Validation of such an approach for correctly screening glaucoma patients has been investigated: a study performed at the Atlanta Veterans Affair Hospital confirmed a high rate of agreement for glaucoma/ glaucoma suspect diagnoses between face-to-face examination and teleglaucoma evaluation in new patients presenting for comprehensive evaluation [22・•]. The ability of teleglaucoma to identify and escalate care for at-risk patients offers significant public health benefits. Staffieri et al. used telemedicine in the screening of first-degree relatives (FDRs) of patients with advanced glaucoma. Two hundred eleven patients were recruited for examination with $6 \%$ of FDRs already carrying a diagnosis of glaucoma, and another $21 \%$ of patients were identified who either required prompt referral or received a diagnosis of glaucoma suspect or ocular hypertension [22••]. The Philadelphia Telemedicine Glaucoma Detection and Follow-up Study utilized trained ophthalmic technicians to obtain IOP measurements, anterior segment, and fundus photographs in a primary care setting. Over $35 \%$ of patients who were screened were determined to have suspicious optic nerves or ocular hypertension [24, 25]. In developing countries with high-risk populations, teleglaucoma screening is similarly able to detect high rates of glaucoma and ocular hypertension, identifying patients who need further care to avoid potentially irreversible vision loss [26]. Studies such as these suggest an important role for teleglaucoma screening to identify patients at risk for glaucoma who may otherwise go undetected (Table 1).

Cost-effectiveness analyses of teleglaucoma screening demonstrate tremendous cost savings for the health care system with one study estimating as high as an $80 \%$ reduction in cost for teleglaucoma screening compared to in-person examination. Furthermore, it reduces patient travel time 
Table 1 Articles on the use of teleglaucoma for triage and screening

\begin{tabular}{|c|c|c|c|c|}
\hline Article & $\begin{array}{l}\text { Type of } \\
\text { teleglaucoma }\end{array}$ & Number of patients & Design of study & Findings of study \\
\hline $\begin{array}{c}\text { Roberts } \\
\text { et al., } \\
2014\end{array}$ & Asynchronous & $\begin{array}{l}1639 \text { patient } \\
\text { identified as } \\
\text { at-risk for } \\
\text { glaucoma }\end{array}$ & $\begin{array}{l}\text { - Initial in person assessment by optometrist } \\
\text { (BCVA, SLE, IOP, CCT, HVF, ONH } \\
\text { photography) } \\
\text { - Notes from initial examination, HVF, and } \\
\text { ONH photos then assessed by glaucoma } \\
\text { specialists } \\
\text { - Primary outcome: accuracy of optometrist } \\
\text { assessments compared to glaucoma specialist }\end{array}$ & $\begin{array}{l}\text {-29.6\% of optic nerve head photos were unable } \\
\text { to be reviewed due to poor image quality } \\
\text { - optometrists had between } 47.5-64.6 \% \\
\text { agreement with glaucoma specialists } \\
\text { regarding diagnosis of glaucoma depending } \\
\text { on optometrist glaucoma training level } \\
\text { Community-based optometry screening has } \\
\text { acceptable levels of accuracy to keep } \\
\text { low-risk patients from seeking unnecessary } \\
\text { glaucoma evaluation }\end{array}$ \\
\hline $\begin{array}{c}\text { Kennan } \\
\text { et al., } \\
2015\end{array}$ & $\begin{array}{l}\text { Asynchronous, } \\
\text { community-- } \\
\text { based services }\end{array}$ & $\begin{array}{l}1733 \text { patients } \\
\text { identified as } \\
\text { glaucoma suspect } \\
\text { by outside } \\
\text { provider }\end{array}$ & $\begin{array}{l}\text { - Remote review of tonometry, pachymetry, } \\
\text { disc photos and HVF by optometrist } \\
\text {-Validation was performed by glaucoma } \\
\text { specialist } \\
\text { - Primary outcome: identification of false } \\
\text { positive referrals }\end{array}$ & $\begin{array}{l}\text { - } 46.6 \% \text { of patients were discharged without } \\
\text { evidence of glaucoma by optometrist initial } \\
\text { review } \\
\text { - } 5.7 \% \text { more patients were discharged after } \\
\text { ophthalmologist review } \\
\text { - } 3.6 \% \text { of initially discharged patients were } \\
\text { recalled } \\
\text { - 91.5\% agreement between optometrist and } \\
\text { ophthalmologist on clinical decision-making } \\
\text { Community based glaucoma screening/triage } \\
\text { by optometry safely reduces the number of } \\
\text { false-positive glaucoma referrals }\end{array}$ \\
\hline $\begin{array}{c}\text { Staffieri } \\
\text { et al. } \\
2011\end{array}$ & Asynchronous & $\begin{array}{l}211 \text { first-degree } \\
\text { relatives (FDR) of } \\
\text { advanced } \\
\text { glaucoma patients }\end{array}$ & $\begin{array}{l}\text { - Initial assessment performed by trained } \\
\text { registered nurse, optometrist, orthoptist or } \\
\text { ophthalmology registrar trainee including } \\
\text { BCVA, HVF, IOP, CCT, and ONH photos } \\
\text { - Virtual images were then reviewed by a } \\
\text { glaucoma specialist } \\
\text { - Primary outcome: use of telemedicine to } \\
\text { determine incidence of undiagnosed } \\
\text { glaucoma in a high-risk population }\end{array}$ & $\begin{array}{l}\text { - } 6 \% \text { of FDRs were already diagnosed with } \\
\text { glaucoma } \\
\text { - another } 5 \% \text { were identified for prompt referral } \\
-15 \% \text { of patients were identified as glaucoma } \\
\text { suspects } \\
-6 \% \text { of patients were ocular hypertensives } \\
\text { Telemedicine is an efficient way to screen high } \\
\text { risk populations for glaucoma }\end{array}$ \\
\hline $\begin{array}{l}\text { Maa } \\
\text { et al. } \\
2020\end{array}$ & $\begin{array}{l}\text { Asynchronous } \\
\text { versus face to } \\
\text { face (FTF) }\end{array}$ & $\begin{array}{l}256 \text { patients with no } \\
\text { known ocular } \\
\text { disease }\end{array}$ & $\begin{array}{l}\text { - Patients scheduled in comprehensive clinic } \\
\text { evaluation included BCVA, pupils, IOP, } \\
\text { CCT, AC depth, AC photo, and dilated } \\
\text { retinal photo } \\
\text { - Patients evaluated in person by a } \\
\text { comprehensive ophthalmologist } \\
\text { - Digital images and clinical history were } \\
\text { reviewed by two blinded ophthalmologists } \\
\text { - Primary outcome: agreement between } \\
\text { evaluations performed virtual versus } \\
\text { face-to-face }\end{array}$ & $\begin{array}{l}\text { - } 86.3 \% \text { and } 84.0 \% \text { agreement on the diagnosis } \\
\text { of glaucoma or glaucoma suspect between } \\
\text { FTF examination and virtual image review } \\
\text { for reader } 1 \text { and reader } 2 \text {, respectively } \\
\text { - There was } 87.5 \% \text { agreement between reader } 1 \\
\text { and reader } 2 \\
\text { Teleglaucoma screening is accurate compared } \\
\text { to face-to-face examination for the diagnosis } \\
\text { of glaucoma and glaucoma suspect }\end{array}$ \\
\hline $\begin{array}{l}\text { Hark } \\
\text { et al. } \\
2017 \\
\text { and } \\
2018\end{array}$ & $\begin{array}{l}\text { Asynchronous, } \\
\text { community-- } \\
\text { based services }\end{array}$ & $\begin{array}{l}906 \text { patients without } \\
\text { known ocular } \\
\text { disease }\end{array}$ & $\begin{array}{l}\text { - Trained technicians went to community health } \\
\text { centers and obtained testing: VA, IOP, } 2 \\
\text { fundus photographs, and } 1 \text { anterior segment } \\
\text { image } \\
\text { - Images were read by a glaucoma specialist and } \\
\text { trained retina reader } \\
\text { - Primary outcome: the ability to detect } \\
\text { glaucoma and other eye diseases in a primary } \\
\text { care setting }\end{array}$ & $\begin{array}{l}-28.5 \% \text { of patients had suspicious optic nerves } \\
-6.8 \% \text { of patients had ocular hypertension } \\
-17.1 \% \text { of images were unreadable } \\
\text { Teleglaucoma screening was able to identify a } \\
\text { large number of patients with concerning } \\
\text { optic nerves and ocular hypertension }\end{array}$ \\
\hline $\begin{array}{r}\text { Giorgis } \\
\text { et al. } \\
2019\end{array}$ & Asynchronous & $\begin{array}{l}1002 \text { Ethiopian } \\
\text { patients }\end{array}$ & $\begin{array}{l}\text { - Patients were screened by a trained ophthalmic } \\
\text { nurse and optometrist with VA, IOP, CCT, } \\
\text { and optic nerve head photos } \\
\text { - A trained glaucoma specialist reviewed the } \\
\text { images and clinical data and a glaucoma } \\
\text { diagnosis was made based on nerve } \\
\text { appearance and IOP } \\
\text { - Primary outcome: the prevalence of glaucoma } \\
\text { detected through teleglaucoma method }\end{array}$ & $\begin{array}{l}\text { - } 13.8 \% \text { of patients were given a diagnosis of } \\
\text { glaucoma suspect } \\
-7.9 \% \text { of patients were diagnosed with } \\
\text { glaucoma } \\
-0.7 \% \text { of patients were referred to a glaucoma } \\
\text { surgeon for further evaluation } \\
\text { Teleglaucoma screening detected a high } \\
\text { prevalence of glaucoma in an Ethiopian } \\
\text { population }\end{array}$ \\
\hline
\end{tabular}


significantly, thereby reducing cost for patients [27•]. Time savings are also seen in reduced appointment times relative to real time face-to-face evaluation by a glaucoma specialist [28].

\section{Teleglaucoma for Disease Management}

In addition to screening, teleglaucoma offers the opportunity for remote management of glaucoma. Clarke et al. compared the efficiency of clinical decision-making for the management of glaucoma in patients seen via teleglaucoma to those seen in face-to-face encounters. Of the 204 patients seen, there were only 7 patients identified in whom there was a failure to escalate care with teleglaucoma that was seen during in-person consultation. There was fair interobserver agreement between the five glaucoma specialists reviewing records and the inperson assessment. The authors conclude that given the slow progressive nature of glaucoma and the low rate of adverse disagreement that teleglaucoma is a safe method for certain glaucoma patients [29]. The true advantages of a teleglaucoma system for management are improved access to specialist care and reduced patient burden as evidenced in the study by Arora et al. that showed decreased access time to glaucoma specialists and reduced time spent in the clinic [30]. Furthermore, teleglaucoma can assist with remote management of patients being followed by their local optometrist. Verma et al. used a combined synchronous/asynchronous model of teleglaucoma consultation for disease management. Of the 273 patients seen via teleglaucoma, 171 patients were able to continue care with their local optometrist, with $48 \%$ of these patients having follow-up teleglaucoma consultations for disease management. Models such as this demonstrate the potential for glaucoma co-management to improve access to care for patients and reduce the number of in-person visits to a glaucoma specialist (Table 2). [31]

\section{The Use of Teleglaucoma in Education}

As an additional consideration, it is hard to ignore the potential utilization of teleglaucoma for educational purposes. The large number of images obtained through a teleglaucoma model can easily be used to expand learning for medical students, residents, and fellows. Studies have shown positive results of incorporating telemedicine into medical education $[32,33]$. Large-scale screening programs are likely to acquire images of less commonly detected pathologies generating a library of images for study. Educational opportunities also extend to low-resource countries where teleglaucoma consultation can augment clinical teaching for local ophthalmologists [34]. Atypical patients may produce a digital catalog of images and clinical data can easily be shared between multiple glaucoma specialists for discussion of difficult management decisions. Serial photographs utilized in teleglaucoma may also allow us to develop a better understanding of the progression of glaucoma [35].

\section{Patient Perceptions of Teleglaucoma}

It is important to consider the patient's perspective when thinking about the use of telemedicine. One study demonstrated that just under $75 \%$ of patients were amenable to receiving teleglaucoma care. Patient perceptions of telemedicine were influenced by a number of factors, including patient age and education [36]. Despite these predispositions, patients enrolled in teleglaucoma programs show high satisfaction. Of the patients who were examined in a local health clinic with a video slit lamp, nonmydriatic fundus, and videoconferencing with a glaucoma specialist at a university clinic, $96 \%$ requested follow-up visit at the local health care clinic over the university clinic. Patients cite decreased travel time, cost savings, and time savings as the most important reasons for preference of telemedicine over in person consultation [37•]. Teleglaucoma visits require significantly less in-office time for patients, reducing the burden on patients [30, 38]. Additionally, patients seen in virtual clinics have a good understanding of their diagnosis with virtual patients demonstrating non-inferior knowledge of their condition compared to in-person clinics [39].

\section{Considerations for Incorporating Teleglaucoma into a Clinical Practice}

The recent COVID-19 pandemic forced a majority of glaucoma providers to incorporate some aspect of telemedicine into their clinical practice $[9,40]$. For many providers, this trend has reversed with the reduced case numbers and increased number of vaccinated patients. However, about $50 \%$ of glaucoma providers plan to continue using telemedicine to provide care for glaucoma patients after the pandemic [9]. For these providers, it is important to consider which requirements are necessary for successful teleglaucoma implementation, including trained personnel to perform diagnostic testing, videoconferencing and data storage equipment, tools for clinical evaluation, and diagnostic equipment, to name a few [18•].

\section{Personnel}

A key component to any teleglaucoma program is the personnel acquiring relevant history and performing clinical and diagnostic testing $[11 \bullet]$. This can include ophthalmic technicians, nurses, or optometrists. Well-trained personnel obtaining images can attenuate high numbers of uninterpretable images that would require return visits for 


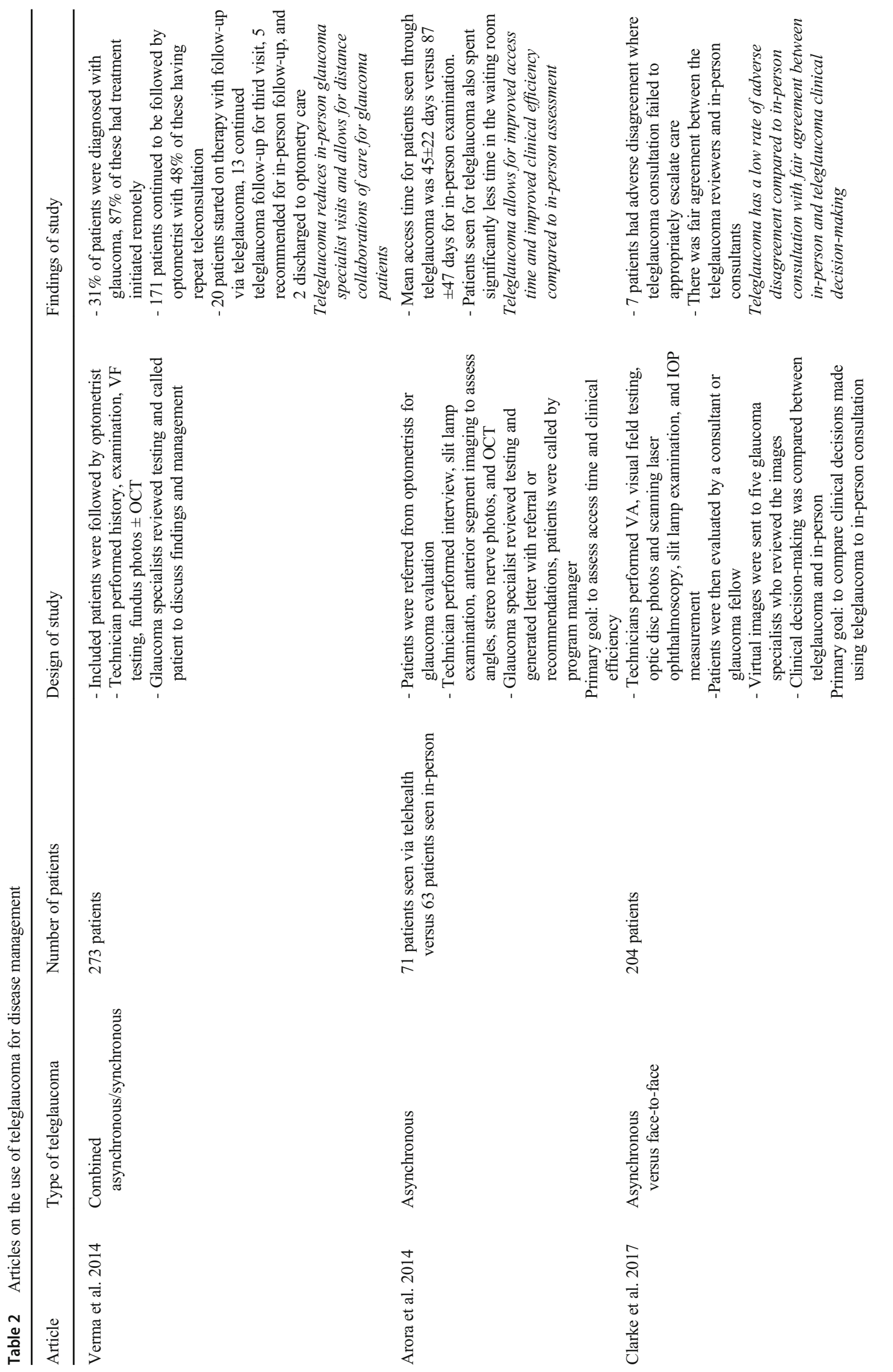


patients. After images have been obtained, they should be reviewed by a trained glaucoma specialist in a timely manner [27•]. The results of the review must then be communicated to the patient either by a trained member of the teleglaucoma team or by the physician directly. This team member must be prepared to counsel and educate the patient on their diagnosis and/or management decisions. Several studies demonstrated the benefit of coordinating care with local optometrists who can perform a large portion of these tasks $[20,21,31]$.

\section{Equipment}

Unlike TeleRetina screening programs, which require only fundus photography, teleglaucoma screening requires measurement of IOP as well as structure and function testing of the optic nerve $[41,42]$. The more diagnostic testing obtained in a teleglaucoma visit, the better the diagnostic decisionmaking of the specialist reviewing the data. Fortunately, advances in glaucoma diagnostics have made acquisition of such data easier with many tests providing digital read outs or digital images that can be compiled for review. Here we will discuss the various aspects of the examination and the necessary equipment to obtain these measurements.

IOP measurement is essential for both the diagnosis and management of glaucoma. While applanation tonometry remains the gold standard, newer methods such as rebound tonometry allow for quick IOP measurement without positioning in a slit lamp or topical anesthetic and can be easily incorporated into a telehealth visit. The iCare HOME also allows for accurate home measurement of IOP and provides useful information on diurnal IOP curves improving remote decision-making for glaucoma providers $[43,44]$. While such systems exist, they do require in-person training and manual download of measurements. Furthermore, these systems are expensive and readings depend on accurate patient administration which can be challenging for visually impaired patients. This is potentially a large barrier to more wide-spread use of teleglaucoma monitoring. CCT also offers important information in the diagnosis and management of glaucoma. Pachymetry can be performed easily by a trained technician using a number of different devices: ultrasound pachymeter, optical lowcoherence reflectometry, Pentacam Scheimpflug imaging, and noncontact specular microscopy. Several portable pachymeter devices exist that can be easily transported $[45,46]$. Visual field testing with standard automated perimetry is critical to teleglaucoma and is commonly obtained with either the Humphrey Field Analyzer (Carl Zeiss Meditec, Jena, Germany) or the Octopus Perimeter (Haag-Streit, Koniz, Switzerland). These tests require patients to present to an office setting and should be performed by trained ophthalmic technicians $[42,47]$. There are currently a handful of tablet and virtual reality testing systems under development which may improve remote monitoring of visual fields in glaucoma patients [48-50]. Optic nerve assessment involves both optic disc photography for qualitative evaluation of the nerve and quantitative structural analysis with OCT. Standard equipment for acquiring optic nerve photos and OCTs are bulky and require in-person visits for images to be obtained. Portable fundus cameras and OCT machines are under evaluation for clinical use and show promise for the tele-evaluation of glaucoma patients [51, 52]. There is certainly a trend toward portable diagnostic tools, several of which interface with smart phones that will likely enhance the future use of teleglaucoma both for patient monitoring and for expanding the scope of tele-screening in glaucoma but this is still an area that needs improvement $[53,54]$. To truly expand the use of teleglaucoma and ensure it is a reliable, accurate, and efficient method of delivering care to patients, we need more dependable, cost effective, and ideally portable methods with which to obtain these images and clinical data.

\section{Other Considerations}

Legal considerations are another crucial aspect of teleglaucoma incorporation into clinical practice. The first of these is informed consent, which is required from the patient for teleglaucoma participation. Patients must understand the nature of the services provided by teleglaucoma as well as their limitations. It is of utmost importance that patients recognize that refusal of teleglaucoma services does not preclude them from in-person care. The potential of patient images to be used for research also requires patient consent [55*0]. Previous regulatory issues required that the physician participating in telehealth reviews must be licensed in the state where the patient is located which certainly limited patient access to virtual subspecialty care. The COVID-19 pandemic required rapid expansion of telehealth services and such licensing policies were amended; however, it is unclear how long this regulatory pause will be effective [55•*, 56]. Additionally, physician liability is a concern. It starts with the understanding that tele-consultation constitutes a patient-physician relationship and mandates HIPAA compliance. Any consultation with other physicians requires patient consent. Review of clinical data and communication with the patient is also the legal responsibility of the physician, and any technician-interpreted clinical data requires physician oversite [11•]. As the use of telemedicine continues to expand, it is likely that many of these legal considerations will be addressed by state and federal regulations.

\section{Conclusions}

Glaucoma is one of the most common causes of blindness worldwide. Teleglaucoma programs can be used in a number of ways to augment current clinical practices, allowing for improved access to screening in high-risk populations and in resource-limited areas. It can also reduce unnecessary specialist appointments and improve co-management programs in remote locations. This results in cost and time savings for the health care system and patients alike, thus reducing the 
burden of disease. However, implementing a full-scale teleglaucoma program requires trained personnel and sufficient equipment in order to allow for the most accurate and effective clinical decision-making. Many new advances in diagnostic imaging allow for remote, in-home monitoring of patients allowing for expansion of teleglaucoma programs, but there is still work to be done.

\section{Declarations}

Conflict of interest The authors declare no competing interests.

\section{References}

Papers of particular interest, published recently, have been highlighted as:

- Of importance

•. Of major importance

1. Tham YC, Li X, Wong TY, Quigley HA, Aung T, Cheng CY. Global Prevalence of Glaucoma and Projections of Glaucoma Burden through 2040: a systematic review and meta-analysis. Ophthalmology. 2014;121:2081-90.

2. Friedman DS, Wolfs RC, O'Colmain BJ, et al. Prevalence of openangle glaucoma among adults in the United States. Arch Ophthalmol. 2004;122(4):532-8.

3. Kass MA, Heuer DK, Higginbotham EJ, Johnson CA, Keltner JL, Miller JP, et al. The Ocular Hypertension Treatment Study: a randomized trial determines that topical ocular hypotensive medication delays or prevents the onset of primary open-angle glaucoma. Arch Ophthalmol. 2002;120(6):701-13.

4. Heijl A, Leske MC, Bengtsson B, Hyman L, Bengtsson B, Hussein $\mathrm{M}$, et al. Early Manifest Glaucoma Trial Group. Reduction of intraocular pressure and glaucoma progression: results from the Early Manifest Glaucoma Trial. Arch Ophthalmol. 2002;120(10):1268-79.

5. Collaborative Normal-Tension Glaucoma Study Group. Comparison of glaucomatous progression between untreated patients with normaltension glaucoma and patients with therapeutically reduced intraocular pressure. Am J Ophthalmol. 1998;126:487-97.

6. Owsley C, McGwin G, Scilley K, Girkin CA, Phillips JM, Searcey K. Perceived barriers to care and attitudes about vision and eye care: focus groups with older African Americans and eye care providers. Invest Ophthalmol Vis Sci. 2006;47(7):2797-802.

7. Bashur RL, Armstrong PA. Telemedicine: A New Mode for the Delivery of Health Care. Inquiry. 1976;13(3):233-44.

8. Demeke HB, Pao LZ, Clark H, et al. Telehealth practice among health centers during the COVID-19 pandemic - United States, July $11-17^{\text {th }}, 2020$. https://www.cdc.gov/mmwr/volumes/69/wr/ mm6950a4.htm?s cid=mm6950a4 w.

9. Capitena Young CE, Patnaik JL, Seibold LK, Kahook MY. Attitudes and perceptions toward virtual health in eye care during coronavirus disease 2019. Telemed J E Health. 2021. https://doi. org/10.1089/tmj.2020.0424.

10. Tan IJ, Dobson LP, Bartnik S, et al. Real-time teleophthalmology versus face-to-face consultation: a systematic review J Telemed Telecare 2016 0(0): 1-10.

11. Trese M, Chiang M, Lee P, et al. AAO Telemedicine Task Force. Telemedicine for Ophthalmology Information Statement, AAO
2018. https://www.aao.org/clinical-statement/ telemedicineophthalmology-information-statement. This paper published by the American Academy of Ophthalmology discusses the use of telemedicine in ophthalmology. It emphasizes potential issues that may arise from the use of tele-ophthalmology including validation issues, the impact of telemedicine on ophthalmology and potential legal and insurance issues that teleophthalmology might face.

12. Li HK, Tang KO, Koplos C, et al. Telemedicine screening of glaucoma. Telemed J. 1999;5(3):283-90.

13. Caffery LJ, Taylor M, Gole G, Smith AC. Models of care in teleophthalmology: a scoping review. J Telemed Telecare. 2019;25(2): 106-22.

14. Lam PY, Chow SC, Lai JSM, Choy BNK. A review on the use of telemedicine in glaucoma and possible roles in COVID-19 outbreak. Surv Ophthalmol. 2021;31:S0039-6257(21)00081-3. https://doi.org/10.1016/j.survophthal.2021.03.008.

15. Nathoo N, Ng M, Rudinsky CJ, et al. The prevalence of diabetic retinopathy as identified by teleophthalmology in rural Alberta. Can J Ophthalmol. 2010;45:28-32.

16. $\mathrm{Ng} \mathrm{M}$, Nathoo $\mathrm{N}$, Rudinsky CJ, et al. Improving access to eye care: teleophthalmology in Alberta, Canada. J Diabetes Sci Technol. 2009;3:289-96.

17. Avidor D, Loewenstein A, Waisbourd M, Nutman A. Costeffectiveness of diabetic retinopathy screening programs using telemedicine: a systematic review. Cost Eff Resour Alloc. 2020;18:16.

18. Thomas SM, Jeyaraman M, Hodge WG, et al. The effectiveness of teleglaucoma versus in-patient examination for glaucoma screening: a systematic review and meta-analysis. PLoS One. 2014;9(12): e1 13779 This was a systematic review of the literature on teleglaucoma focused on diagnostic accuracy and cost effectiveness. By estimating pooled sensitivity and specificity from over 45 studies, the study concluded that teleglaucoma can accurately screen for glaucoma and that is offers cost and time savings to both the healthcare system and the patient.

19.• Gupta SC, Sinha SK, Dagar AB. Evaluation of the effectiveness of diagnostic \& management decision by teleophthalmology using indigenous equipment in comparison with in-clinic assessment of patients. Indian J Med Res. 2013;138:531-5 In this study, patients were screened both by teleophthalmology and an in-person ophthalmologist. For the diagnosis of anterior segment pathology, there was good to very good agreement between the two screening methods. For the diagnosis of glaucoma and retinal diseases, there was moderate agreement. There was also moderate agreement on disease management decisions between the two ophthalmologists for all eye pathology.

20. Roberts HW, Rughani K, Syam P, Dhingra S, Ramirez-Florez S. The Peterborough Scheme for Community Specialist Optometrists in Glaucoma: results of 4 years of a two-tiered community-based assessment and follow-up service. Curr Eye Res. 2015;40(7):690-6.

21. Kennan J, Shahid H, Bourse RR, et al. Cambridge community optometry glaucoma scheme. Clin Exp Ophthalmol. 2015;43(3): 221-7.

22.• Maa AY, Medert CM, Lu X, et al. Diagnostic Accuracy of Technology-based Eye Care Services: the technology-based eye care services compared trial part I. Ophthalmology. 2020;127: 38-44 This study sought to validate the accuracy of teleophthalmology screening by comparing diagnoses obtained during face-to-face (FTF) examinations to those reached by ophthalmologists virtually reviewing digital images (Technology-based Eye Care Services or TECS). There was substantial agreement between FTF and TECS examination for cataract and diabetic retinopathy and moderate to substantial agreement for the diagnosis of glaucoma/glaucoma suspect. This study concluded that the TECS evaluation is accurate compared to FTF examinations. 
23. Staffieri SE, Ruddle JB, Kearns LS, Barbour JM, Edwards TL, Paul $\mathrm{P}$, et al. Telemedicine model to prevent blindness form familial glaucoma. Clin Exp Ophthalmol. 2011;39:760-5.

24. Hark L, Acito M, Adeghate J, Henderer J, Okudolo J, Malik K, et al. Philadelphia telemedicine glaucoma detection and follow-up study: ocular findings at two health centers. J Health Care Poor Underserved. 2018;29(4):1400-15.

25. Hark LA, Katz LJ, Myers JS, Waisbourd M, Johnson D, Pizzi LT, et al. Philadelphia telemedicine glaucoma detection and follow-up study: methods and screening results. Am J Ophthalmol. 2017;181: 114-24.

26. Giogis AT, Alemu AM, Arora S, et al. Results from the first teleglaucoma pilot project in Addis Ababa. Ethiopia J Glaucoma. 2019;28(8):701-7.

27. Thomas S, Hodge W, Malvankar-Mehta M. The cost-effectiveness analysis of teleglaucoma screening device. PLoS One. 2015;10(9): e 0137913 This study investigated the cost-effectiveness of teleglaucoma using healthcare provider or third-party payer data. The study found a reduction in referral rates, patient travel time and physician wait times with the utilization of teleglaucoma. Teleglaucoma also proved to be more cost effective than in-person examinations.

28. Sommer AC, Blumenthal EZ. Telemedicine in ophthalmology in view of the emerging COVID-19 outbreak. Graefes Arch Clin Exp Ophthalmol. 2020;19:1-12.

29. Clarke J, Puertas R, Kotecha A, Foster PJ, Barton K. Virtual clinics in glaucoma care: face-to-face versus remote decision-making. Br J Ophthalmol. 2017;101:892-5.

30. Arora S, Rundinsky CJ, Damji KF. Improved access and cycle time with an "in-house" patient-centered teleglaucoma program versus traditional in-person assessment. Telemedicine and e-Health. 2014;20(5):439-45.

31. Verma S, Arora S, Kassam F, Edwards MC, Damji KF. Northern Alberta remote teleglaucoma program: clinical outcomes and patient disposition. Can J Ophthalmol. 2014;49:135-40.

32. O'Shea J, Berger R, Samra C, et al. Telemedicine in education: bridging the gap. Educ Health. 2015;28(1):64-7.

33. Demartines N, Mutter D, Vix M, Leroy J, Glatz D, Rösel F, et al. Assessment of telemedicine in surgical education and patient care. Ann Surg. 2000;231(2):282-91.

34. Littman-Quinn R, Mibenge C, Antwi C, Chandra A, Kovarik CL. Implementation of m-health applications in Botswana: telemedicine and education devices in a low resourse setting. J Telemed Telecare. 2013;19(2):120-5.

35. Kassam F, Yogesan K, Sogbesan E, Pasquale LR, Damji KF. Teleglaucoma: Improving Access and Efficiency for Glaucoma Care. Middle East Afr J Ophthalmol. 2013;20(2):142-9.

36. Rhodes LA, Huisingh CE, McGwin G, Girkin CA, Owsley C. Glaucoma Patient Knowledge, Perceptions, and Predisposition for Telemedicine. J Glaucoma. 2019;28(6):481-6.

37. Tuulone A, Ohinmaa T, Alanko HI, Hyytinen P, Juutinen A, Toppinen E. The application of teleophthalmology in examining patients with glaucoma: a pilot study. J Glaucoma. 1999;8(6): 367-73 This study found that patients who received teleglaucoma services were equally satisfied with their visit compared to in-person examination and nearly all of the teleglaucoma patients preferred to have repeat teleglaucoma examination. Patients cited reduction in traveling, cost and and time as the most important factors for their preference of teleglaucoma over in-person evaluation.

38. Kotecha A, Baldwin A, Brookes H. Experiences with developing and implementing a virtual clinic for glaucoma care in an NHS setting. Clin Ophthalmol. 2015;9:1915-23.
39. Court JH, Austin MW. Virtual glaucoma clinics: patient acceptance and quality of patient education compared to standard clinics. Clin Ophthalmol. 2015;9:745-9.

40. Vinod K, Sidoti P. Glaucoma care during the coronavirus disease 2019 pandemic. Curr Opin Ophthalmol. 2021;32:75-82.

41. Moyer VA, U.S. Preventive Services Task Force. Screening for glaucoma: U.S. Preventive Services Task Force Recommendation Statement. Ann Intern Med. 2013;159(7):484-9.

42. Prum BE, Lim MC, Mansberger SL, et al. Primary open-angle glaucoma suspect preferred practice pattern guidelines. Ophthalmology. 2016;123(1):P112-51.

43. McGarva E, Farr J, Dabasia P, Lawrenson JG, Murdoch IE. Initial experience in self-monitoring of intraocular pressure. Eur J Ophthalmol. 2020:27. https://doi.org/10.1177/1120672120920217.

44. Chen E, Querat L, Akerstedt C. Self-tonometry as a complement in the investigation of glaucoma patients. Acta Ophthalmol. 2016;94(8):788-192.

45. Barkana Y, Gerber Y, Elbaz U, Schwartz S, Ken-Dror G, Avni I, et al. Central corneal thickness measurement with the Pentacam Scheimpflug system, optical low-coherence reflectometry pachymeter, and ultrasound pachymeter. J Cataract Refract Surg. 2005;31(9):1729-935.

46. Tai LY, Khaw KW, Ng CM, Subrayan V. Central corneal thickness measurements with different imaging devices and ultrasound pachymetry. Cornea. 2013;32(6):766-71.

47. Monslave B, Ferreras A, Calvo P, et al. Diagnostic ability of Humphrey perimetry, Octupus perimetry, and optical coherence tomography for glaucomatous optic neuropathy. Eye(Lond). 2017;31:443-51.

48. Jones PR, Campbel P, Callaghan T, et al. Glaucoma home monitoring using a tablet-based visual field test (Eyecatcher): an assessment of accuracy and adherence over 6 months. Am J Ophthlamol. 2021;223:42-52.

49. Prea SM, Kong YXG, Mehta A, He M, Crowston JG, Gupta V, et al. Six-month longitudinal comparison of a portable tablet perimeter with the Humphrey field analyzer. Am J Ophthalmol. 2018;190:9-16.

50. Mees J, Upadhyaya W, Kumar P, et al. Validation of a headmounted virtual reality visual field screening device. J Glaucoma. 2020;29(2):86-91.

51. Liu X, Kale AU, Capewell N, et al. Optical coherence tomography (OCT) in unconscious and systemically unwell patients using a mobile OCT device: a pilot study. BMJ Open. 2019;11:e030882.

52. Yogesan K, Constable IJ, Barry CJ, Eikelboom RH, Morgan W, Tay-Kearney ML, et al. Evaluation of a portable fundus camera for use in the teleophthalmologic diagnosis of glaucoma. J Glaucoma. 1999;8(5):297-301.

53. Mercado C, Welling J, Oliva M, Li J, Gurung R, Ruit S, et al. Clinical Application of a smartphone-based ophthalmic camera adapter in under-resourced settings in Nepal. J Mob Technol Med. 2017;6(3):34-42.

54. Mohammadpour M, Heidari Z, Mirghorbani M, Hashemi H. Smartphones, tele-ophthalmology, and VISION 2020. Int J Ophthalmol. 2017;10(12):1909-18.

55.• Newton MJ. The promise of telemedicine. Surv Ophthalmol. 2014;59:559-67 This is an excellent review on telemedicine in ophthalmology with a particular emphasis on legal, ethical and professional issues that arise with the use of teleophthalmology.

56. Public Health Institute Center for Connected Health Policy. State telehealth laws and reimbursement policies: a comprehensive scan of the 50 states and district of Columbia. 1997

Publisher's Note Springer Nature remains neutral with regard to jurisdictional claims in published maps and institutional affiliations. 